ISSN 2525-4804

\title{
A IMPORTÂNCIA DO ÁCIDO SALICÍLICO NA MITIGAÇÃO DO DÉFICIT HÍDRICO EM PLANTAS DE CAFEEIRO
}

\author{
Brunno Nunes Furtado ${ }^{1}$, Larissa Pacheco Borges ${ }^{2}$, Victor Alves Amorim3, Fábio Santos Matos ${ }^{4}$
}

\section{RESUMO}

O estresse hídrico em plantas pode ser mitigado a partir da aplicação de substâncias elicitoras que estimulam as diferentes respostas de defesas fisiológicas. $\mathrm{O}$ objetivo deste estudo foi avaliar a efetividade do ácido salicílico (AS) como pré-ativador do sistema de defesa ao déficit hídrico sobre o crescimento e características fotossintéticas de plantas de cafeeiro. O trabalho foi conduzido em casa de vegetação coberta com plástico transparente e laterais com tela que intercepta $50 \%$ da radiação solar. Adotou-se o delineamento experimental inteiramente casualizado em arranjo fatorial 6 x 2, com seis concentrações de AS $(0,0 \mathrm{mM}$; 0,05mM;0,1mM;0,2mM;0,4mM e 0,8 mM) e duas cultivares de cafeeiro (IPR 100 e Tupi) com cinco repetições. O AS foi fornecido aos 100, 120 e 140 dias após a emergência (DAE) através da aplicação foliar. Aos 135 DAE todas as plantas foram submetidas a 10 dias de déficit hídrico severo com suspensão total da irrigação. Aos 145 DAE foram avaliados as variáveis de crescimento, pigmentos fotossintéticos, teor relativo de água e taxa de transpiração. O AS nas concentrações entre 0,05 a 0,8 $\mathrm{mg} \mathrm{L}^{-1}$ levaram a redução do crescimento e acúmulo de biomassa nas cultivares de cafeeiro. O AS não ativou os mecanismos de defesa de plantas de cafeeiro sob déficit hídrico e as concentrações testadas influenciaram negativamente nas características fisiológicas das plantas. Dessa forma, a hipótese de ação do regulador vegetal como elicitor não foi comprovada no presente estudo, no entanto, por se tratar de um tema inovador e incipiente quanto à informações esclarecedoras, registra-se a necessidade de pesquisas futuras e desenvolvimento de trabalhos com concentrações variadas e efetivas para a reprogramação metabólica e fisiológica das plantas.

Palavras-chave: Coffea arabica, priming, substâncias elicitoras.

\section{THE IMPORTANCE OF SALICYLIC ACID IN THE MITIGATION OF WATER DEFICIT IN COFFEE PLANTS}

\section{ABSTRACT}

Water stress in plants can be mitigated through the application of eliciting substances that stimulate different defense physiological responses in plants. The aim of this study was to evaluate the effectiveness of

\footnotetext{
${ }^{1}$ Estudante de Agronomia, Grupo de pesquisa Fisiologia da Produção, Universidade Estadual de Goiás-UEG, Rodovia GO 330 , Km 241, Anel Viário, CEP: 75780-000, Ipameri (GO), Brasil. brunnonunesfurtado10@gmail.com

${ }^{2}$ Engenheira Agrônoma, Pós-doutoranda, Universidade Estadual de Goiás-UEG, Rodovia GO 330, Km 241, Anel Viário, CEP: 75780-000, Ipameri (GO), Brasil. larissa.pb@hotmail.com.br

${ }^{3}$ Engenheiro Agrônomo, Mestrando em Produção Vegetal, Universidade Estadual de Goiás - Campus Ipameri, Rodovia GO-330, Km 241 Anel Viário. Cep: 75780-000. Ipameri (GO), Brasil. victor.alves.a@gmail.com

${ }^{4}$ Engenheiro Agrônomo, Dsc. Prof. Fisiologia Vegetal, supervisor do Grupo de Pesquisa Fisiologia da Produção da Universidade Estadual de Goiás-UEG, Rodovia GO 330, Km 241, Anel Viário, CEP: 75780-000, Ipameri (GO). fabio.agronomia@hotmail.com 
ISSN 2525-4804

salicylic acid (AS) as a pre-activator of the water deficit defense system to growth and photosynthetic characteristics of coffee plants. The work was carried out in a greenhouse covered with transparent plastic and sides with a screen that intercepts $50 \%$ of solar radiation. The experimental design was completely random in a $6 \times 2$ factorial arrangement, with six concentrations of AS $(0.0 \mathrm{mM}, 0.05 \mathrm{mM}, 0.1 \mathrm{mM}, 0.2 \mathrm{mM}, 0.4 \mathrm{mM}$ and $0.8 \mathrm{mM}$ ) and two cultivars of coffee plant (IPR 100 and Tupi) with five repetitions. The AS was supplied at 100, 120 and 140 days after emergence (DAE) through foliar application. At 135 DAE, all plants were submitted to 10 days of severe water deficit with total suspension of irrigation. At 145 DAE, growth variables, photosynthetic pigments, relative water content and perspiration rate were evaluated. AS in concentrations between 0.05 to $0.8 \mathrm{mg} \mathrm{L}^{-1}$ led to reduced growth and accumulation of biomass in coffee cultivars. The AS didn't activate the defense mechanisms of coffee plants under water deficit and the tested concentrations had a negative influence on the physiological characteristics of plants. Thus, the hypothesis of action of the plant regulator as an elicitor hasn't been proven in this study. However, the theme of this research is new, incipient and brought clarifying information, it is emphasizes the need to future research and development of works with varied and effective concentrations for metabolic and physiological reprogramming of plants.

Keywords: Coffea arabica, priming, eliciting substances. 


\section{INTRODUÇÃO}

A cultura do café (Coffea arabica) é de grande importância econômica para o Brasil, sendo o quinto item mais exportado do agronegócio brasileiro, depois de outros commodities agrícolas como a soja, carnes, produtos florestais e do complexo sucroalcooleiro (Mapa, 2015). Em 2018 a produção nacional alcançou $61.657,8$ mil sacas, recorde de produtividade brasileira com crescimento de $37,1 \%$ em relação a 2017. Esse incremento se deve, principalmente, pela melhoria da tecnologia empregada na lavoura, bem como pelo uso de variedades mais produtivas no ano positivo da bienalidade (Conab, 2018; Durán et al., 2017).

Apesar do recorde de produção, a produtividade brasileira está abaixo do potencial da cultura do cafeeiro (Fernandes et al., 2012). Isso se deve a problemas no manejo da lavoura e no pouco uso de técnicas mitigadoras de estresses abióticos frequentes como o déficit hídrico. Como reflexo dessa situação, sabe-se que a reduzida disponibilidade de água promove alterações bioquímicas e morfofisiológicas propícias ao comprometimento do crescimento e produtividade (Martins et al., 2018).

Tem-se observado que a produtividade do cafeeiro é constantemente prejudicada pelo depauperamento da cultura sob estresses abióticos, por ocasião de adversidade climática (Ribeiro et al., 2017; Silva et al., 2017). Considerando esse contexto, estudos recentes têm revelado o uso do ácido salicílico (AS) como agente mitigador do déficit hídrico por atenuar os efeitos deletérios da desidratação em plantas (Da Silva et al., 2017; Idrees et al., 2010). Segundo Da Silva et al. 2017, em plantas de gergelim (Sesamum indicum) o AS induziu tolerância ao estresse hídrico, enquanto Lima et al. 2019, concluíram que em feijoeiro (Phaseolus vulgaris) o AS incrementou a massa seca, comprimento de raiz e germinação. O AS é um hormônio vegetal de natureza fenólica que exerce significativa importância reguladora do metabolismo vegetal, principalmente no que tange a ativação do metabolismo antioxidativo sob déficit hídrico (Taiz et al., 2017). Em vista desses estudos, pode-se inferir que o AS, além de ser uma molécula natural sinalizadora para a ativação de defesas da planta, modifica o sistema antioxidante por estimular a ação de enzimas como superóxido dismutase, catalase e peroxidase (Sharma \& Bhardwaj, 2014).

Vinculada a essas evidências, importa ressaltar que a tolerância ao estresse é dependente da pré-ativação (priming) e duração de mecanismos de proteção através de uma espécie de memória da planta, de modo que envolve modificações na transcrição com mudanças na expressão de genes (Duarte et al., 2018; Lamke et al., 2017). Segundo Lamke et al. (2017) e Samota et al. (2017) o AS atua como elicitor indutor de tolerância aos estresses bióticos e abióticos. Dessa forma, como pressupõese, o sistema de defesa da planta é pré-ativado pelo regulador vegetal.

Conforme relatado por Batista et al. (2010), o aumento da produtividade com plena manifestação do potencial genético do cafeeiro, bem como a expansão da fronteira agrícola depende do desenvolvimento de técnicas de manejo inovadoras no sentido de mitigar os estresses em regiões inaptas tornando-as aptas a exploração comercial da cultura.

Diante do exposto, este trabalho foi proposto com o objetivo de avaliar a efetividade do AS como pré-ativador do sistema de defesa ao déficit hídrico e elucidar seus efeitos sobre as características fisiológicas de plantas de cafeeiro.

\section{MATERIAL E MÉTODOS}

A pesquisa foi conduzida na Universidade Estadual de Goiás, Campus Sudeste, UnU Ipameri (Lat. $17^{\circ} 42^{\prime}$ 59,12 S, Long. 48 08'40,49'’W, Alt. 773 m), Ipameri, GO. Essa região possui clima tropical com inverno seco e verão úmido (Aw) de acordo com a classificação de Köppen (Alvares et al., 2013).

Foram utilizadas mudas de cafeeiro das cultivares Tupi e IPR 100 adquiridas de viveiro certificado no município de Araguari-GO, com 60 
dias após a emergência (DAE). As plantas passaram por um período de aclimatação em torno de 20 dias e posteriormente foram transplantadas para vasos de 12 L contendo mistura de solo, areia e esterco na proporção de $3: 1: 0,5$, e cultivadas sob bancadas em casa de vegetação coberta com plástico transparente $(200 \mu \mathrm{m})$ e laterais em sombrite com interceptação de $50 \%$ da radiação solar. O solo utilizado foi classificado como Latossolo Vermelho Amarelo. A análise química da mistura revelou os seguintes valores: $\mathrm{pH}\left(\mathrm{CaCl}_{2}\right) 5,4 ; 16 \mathrm{~g} \mathrm{dm}^{-3}$ de matéria orgânica; $68 \mathrm{mg} \mathrm{dm}^{-3}$ de P; 6,81 mmolc $\mathrm{dm}^{-3}$ de K $\left(\right.$ Mehlich $^{-1}$ ); 22 mmolc dm ${ }^{-3}$ (Tampão SMP) de $\mathrm{H}+$ $\mathrm{Al} ; 31 \mathrm{mmolc} \mathrm{dm}^{-3}$ de Ca; 15 mmolc dm ${ }^{-3}$ de $\mathrm{Mg} ; 53$ mmolc dm ${ }^{-3}$ de SB; 75 mmolc dm$^{-3}$ de CTC; e $71 \%$ de saturação por bases.

O delineamento experimental utilizado foi inteiramente casualizado em arranjo fatorial $6 \times 2$, com seis concentrações de ácido salicílico $(0,0 \mathrm{mM}$; $0,05 \mathrm{mM} ; 0,1 \mathrm{mM} ; 0,2 \mathrm{mM} ; 0,4 \mathrm{mM}$ e $0,8 \mathrm{mM}$ ) e duas cultivares de cafeeiro (Tupi e IPR 100) e cinco repetições. As plantas foram irrigadas de forma manual e diariamente com $100 \%$ do volume de água referente a evapotranspiração.

O volume de água fornecido foi estimado determinando a evapotranspiração de referência e o coeficiente da cultura. Para determinar a evapotranspiração da cultura, utilizou-se a equação:

$$
E T c=E T o x k c
$$

Onde: $\mathrm{ETc}=$ evapotranspiração da cultura; $\mathrm{kc}$ $=$ coeficiente da cultura e ETo = Evapotranspiração de referência

O cálculo da ETo diária foi feito pelo método de Penman-Monteith recomendado pela FAO (Smith et al., 1991) utilizando os dados diários de temperatura máxima e mínima do ar, umidade relativa do ar, insolação e velocidade do vento obtidos na Estação Meteorológica do INMET, número 83522, localizado no município de Ipameri, GO. Como o coeficiente da cultura $(\mathrm{kc})$ para cafeeiro ainda não foi determinado, utilizamos o $\mathrm{kc}$ igual a 1,00 seguindo estimativa da FAO 56 (Allen et al., 1998) para um grupo de culturas em estádio de crescimento inicial.

O AS foi fornecido em aplicação foliar no volume de $30 \mathrm{~mL}$ por planta por aplicação com adição de Tween (óleo mineral) 0,05\% aos 100, 120 e 140 dias após a emergência (DAE). Aos 135 DAE as plantas foram submetidas a 10 dias de déficit hídrico severo com suspensão total da irrigação e aos 145 DAE foram avaliadas as características biométricas relacionadas ao crescimento, tal como os parâmetros fotossíntéticos.

Variáveis de crescimento: A altura de planta foi mensurada a partir da região de transição da raiz com o caule na base da planta rente ao solo (coleto) até o ápice do caule utilizando régua milimétrica. $\mathrm{O}$ número de folhas foi obtido por contagem. $\mathrm{O}$ comprimento da raiz foi avaliado por meio do uso de uma trena graduada. As folhas, raízes e caules foram destacados e colocados para secar em estufa a $72{ }^{\circ} \mathrm{C}$ por 72 horas até atingir massa seca constante e, em seguida, pesados separadamente. Com os dados de massa seca calculou-se a biomassa total somando-se as massas de todas as partes da planta e razões de massa foliar, caulinar e radicular dividindo-se a massa do órgão específico pela biomassa total. A área foliar foi determinada com auxílio do equipamento LI-3100 Área Meter, LI-COR, USA expressando em $\left(\mathrm{cm}^{2}\right)$ e utilizando todas as folhas de cada planta.

Pigmentos fotossintéticos: Para a determinação da concentração de clorofilas foram retirados dois discos foliares de $0,6 \mathrm{~mm}$ de diâmetro cada em folhas totalmente expandidas e colocados em vidros contendo $3 \mathrm{ml}$ de dimetilsulfóxido (DMSO) saturado com carbonato de cálcio $50 \quad\left(\mathrm{~g} \mathrm{~L}^{-1}\right)$. Posteriormente, realizou-se a extração em banhomaria a $65^{\circ} \mathrm{C}$ por uma hora. Retirou-se alíquotas para leitura espectrofotométrica a 480, 646 e $663 \mathrm{~nm}$. O conteúdo de clorofila a $(\mathrm{Cl} a)$ e clorofila b $(\mathrm{Cl} b)$ foram determinados seguindo a equação proposta por Wellburn, (1994). Os resultados foram expressos em $\mathrm{g} \mathrm{kg}^{-1}$.

Teor relativo de água na folha: Para obtenção do teor relativo de água foram retirados cinco discos foliares de $1,2 \mathrm{~cm}$ de diâmetro em folhas 
totalmente expandidas. Estes foram pesados para registrar a massa fresca (MF) e colocados para saturar por 24 horas em placas de Petri com água destilada quando foram novamente pesados e determinada a massa túrgida (MT). Em seguida, colocados para secar à temperatura de $70{ }^{\circ} \mathrm{C}$ por 72 horas, sendo posteriormente obtida a massa seca (MS) e a realização do cálculo do teor relativo de água seguindo a equação: (MF - MS)/(MT - MS).

Taxa de Transpiração: A transpiração diária total da planta foi mensurada pela diferença de peso dos vasos. Inicialmente, cada vaso foi inserido dentro de um saco plástico fixado com borracha no caule da planta, ficando apenas a parte aérea (folhas e caule) externa ao saco. Em seguida, o conjunto vaso com planta e saco plástico foram pesados (massa 01), e 24 horas depois novamente pesados (massa 02). A transpiração total foi estimada pela diferença entre a massa 01 e massa 02.

Procedimentos estatísticos: Os dados foram submetidos à análise de variância (ANOVA) pelo teste $F$ e regressão $(\mathrm{p}<0,05)$ e $(\mathrm{p}<0,01)$; utilizando o software SigmaPlot10 (Sysstat, 2006). A análise multivariada foi feita por meio da regressão múltipla utilizando a seleção do modelo forward stepwise (Sokal e Rolf, 1995) e o software Statistica (Statsoft, 2007). A análise de componentes principais foi realizada utilizando uma análise de variância multivariada por permutação - Permanova (Anderson, 2001) no software Statistica (Statsoft, 2007).

\section{RESULTADOS E DISCUSSÃO}

Os dados referentes à altura de planta, número de folhas, área foliar e comprimento da raiz são mostrados na tabela 1. Os valores referentes a biomassa e razões de área foliar, caulinar e radicular são mostrados na tabela 2 . Na tabela 3 são mostrados os dados de teor relativo de água, transpiração total e concentrações foliares de clorofila $a$ e clorofila $b$.

Tabela 1, Análise de variância e teste de média para altura, número de folhas (NF), área foliar (AF) e comprimento de raiz (Craiz) para duas cultivares (IPR 100 e Tupi) de Coffea arabica submetidas a diferentes concentrações de ácido salicílico e sob déficit hídrico.

\begin{tabular}{|c|c|c|c|c|c|}
\hline \multirow{2}{*}{$\begin{array}{l}\text { Fonte de } \\
\text { Variação }\end{array}$} & \multirow[b]{2}{*}{ GL } & \multicolumn{4}{|c|}{ Quadrados Médios } \\
\hline & & $\begin{array}{c}\text { Altura } \\
\text { (cm) }\end{array}$ & NF & $\begin{array}{c}\mathrm{AF} \\
\left(\mathrm{cm}^{2}\right)\end{array}$ & $\begin{array}{l}\text { Craiz } \\
(\mathrm{cm})\end{array}$ \\
\hline Cultivar & 1 & $674 * *$ & $123^{\mathrm{ns}}$ & $102116^{\mathrm{ns}}$ & $7^{\mathrm{ns}}$ \\
\hline Concentração & 5 & $136^{*}$ & $1188^{\mathrm{ns}}$ & $531619 * *$ & $16^{\mathrm{ns}}$ \\
\hline Cult*Conc & 5 & $69^{\mathrm{ns}}$ & $272^{\mathrm{ns}}$ & $608848^{\mathrm{ns}}$ & $4^{\mathrm{ns}}$ \\
\hline Resíduo & 36 & 50 & 496 & 61457 & 14 \\
\hline $\mathrm{CV}(\%)$ & & 18,8 & 34,4 & 20,6 & 20,7 \\
\hline Tratamento & & \multicolumn{4}{|c|}{ Médias } \\
\hline 0 & & $43,9(100 \%)$ & $81(100 \%)$ & $1442(100 \%)$ & $17,7(100 \%)$ \\
\hline 0,05 & & $38,6(88 \%)$ & $66(81 \%)$ & $1294(90 \%)$ & $17,8(101 \%)$ \\
\hline 0,1 & & $39,4(90 \%)$ & $64(79 \%)$ & $1424(98 \%)$ & $18(102 \%)$ \\
\hline 0,2 & & $38,4(87 \%)$ & $70(86 \%)$ & $1262(88 \%)$ & $20,1(114 \%)$ \\
\hline 0,4 & & $34,9(79 \%)$ & $63(78 \%)$ & $999(69 \%)$ & $21,1(119 \%)$ \\
\hline 0,8 & & $31,8(72 \%)$ & $43(53 \%)$ & $788(55 \%)$ & $16,6(94 \%)$ \\
\hline
\end{tabular}

*significativo a $5 \%$ de probabilidade; $* *$ significativo a $1 \%$ de probabilidade; $\mathrm{ns}=$ não significativo pelo teste $\mathrm{F}$. 
Tabela 2. Análise de variância e teste de média para biomassa, razão de massa foliar (RMF), razão de massa caulinar (RMC) e razão de massa radicular (RMR) para duas cultivares (IPR 100 e Tupi) de Coffea arabica submetidas a diferentes concentrações de ácido salicílico e sob déficit hídrico.

\begin{tabular}{|c|c|c|c|c|c|}
\hline \multirow{2}{*}{$\begin{array}{l}\text { Fonte de } \\
\text { Variação }\end{array}$} & \multirow[b]{2}{*}{ GL } & \multicolumn{4}{|c|}{ Quadrados Médios } \\
\hline & & $\begin{array}{c}\text { Biomassa } \\
\text { (g) }\end{array}$ & RMF & RMC & RMR \\
\hline Cultivar & 1 & $124^{\mathrm{ns}}$ & $0,0000009^{\mathrm{ns}}$ & $0,006^{\mathrm{ns}}$ & $0,015^{\text {ns }}$ \\
\hline Concentração & 5 & $150 *$ & $0,00004^{\mathrm{ns}}$ & $0,01^{\mathrm{ns}}$ & $0,012^{\mathrm{ns}}$ \\
\hline Cult*Conc & 5 & $135^{*}$ & $0,00002^{\mathrm{ns}}$ & $0,02^{\mathrm{ns}}$ & $0,025^{\text {ns }}$ \\
\hline Resíduo & 36 & 50 & 0,00001 & 0,01 & 0,013 \\
\hline $\mathrm{CV}(\%)$ & & 36,3 & 34,4 & 22 & 25,2 \\
\hline Tratamento & & \multicolumn{4}{|c|}{ Médias } \\
\hline 0 & & $24,5(100 \%)$ & $0,02(100 \%)$ & $0,53(100 \%)$ & $0,44(100 \%)$ \\
\hline 0,05 & & $20,4(83 \%)$ & $0,03(150 \%)$ & $0,51(96 \%)$ & $0,45(102 \%)$ \\
\hline 0,1 & & $20,8(85 \%)$ & $0,02(100 \%)$ & $0,49(92 \%)$ & $0,50(114 \%)$ \\
\hline 0,2 & & $19,6(80 \%)$ & $0,02(100 \%)$ & $0,50(94 \%)$ & $0,47(107 \%)$ \\
\hline 0,4 & & $18,4(75 \%)$ & $0,03(150 \%)$ & $0,51(96 \%)$ & $0,47(107 \%)$ \\
\hline 0,8 & & $10,8(44 \%)$ & $0,03(150 \%)$ & $0,60(113 \%)$ & $0,38(86 \%)$ \\
\hline
\end{tabular}

*significativo a $5 \%$ de probabilidade; **significativo a $1 \%$ de probabilidade; ns= não significativo pelo teste $\mathrm{F}$.

A altura de plantas de café para as duas cultivares avaliadas apresentaram respostas significativas em relação às concentrações de AS utilizado (Figura 1). A cultivar Tupi ajustou-se ao modelo linear de regressão, constatando-se que no tratamento controle $\left(0 \mathrm{mg} \mathrm{L}^{-1}\right)$ a altura atingiu 47,4 $\mathrm{cm}$, e na concentração máxima utilizada $\left(0,8 \mathrm{mg} \mathrm{L}^{-1}\right)$ houve redução de $19,4 \%$. Para a cultivar IPR 100 registrou-se um decréscimo da altura até a concentração $0,53 \mathrm{mg} \mathrm{L}^{-1}(35 \mathrm{~cm})$ e posteriormente aumento na altura das plantas até $38,2 \mathrm{~cm}$ na concentração de $0,8 \mathrm{mg} \mathrm{\textrm {L } ^ { - 1 }}$. Foram observadas alterações no número de folhas apenas na cultivar Tupi, com redução de $29,8 \%$ à medida que ocorreu aumento das concentrações do AS. Segundo Carvalho et al. (2016), a cultivar IPR 100 por ser portadores de genes do Coffea liberica Hiern, mostrase mais tolerantes à estresses do que outros cafeeiros. Sendo assim, o AS que foi utilizado com a finalidade de mitigar os efeitos do déficit hídrico, tem poucas respostas nestas cultivares mais tolerantes.

Com relação a área foliar das plantas de cafeeiro, foram detectadas reduções para todas as concentrações utilizadas em relação ao tratamento controle. Logo, os dados demonstram reduções da área foliar de 37,6\% para IPR 100 e 54,48\% para Tupi. As duas cultivares ajustaram-se ao modelo de regressão linear para área foliar. Sendo assim, o menor desenvolvimento das plantas com a utilização do AS explica a menor biomassa total obtida. No tratamento controle a biomassa da cultivar Tupi foi de 22,3 g. Assim, à medida que as concentrações aumentavam a biomassa total reduzia. Essa redução foi de até $61 \%$ na máxima concentração utilizada.

Não foram observadas diferença significativa para o comprimento de raiz, teor relativo de água, transpiração e clorofila $a$ e $b$, em resposta à aplicação de AS (Tabelas 1 e 3). Na Tabela 3 são apresentados os resultados da análise dos teores de clorofilas presentes em folhas das cultivares de cafeeiro. Comparando-se o efeito das diferentes concentrações de AS sobre os índices de clorofila ( $a$ e $b$ ) nas cultivares de cafeeiro, verificou-se que não houve diferença significativa entre os teores de clorofila $a$ que foram em média de $3,36 \mathrm{~g} \mathrm{~kg}^{-1}$ em folhas de Tupi e $3,14 \mathrm{~g} \mathrm{~kg}^{-1}$ para IPR 100. Enquanto para a clorofila 
b, 5,64 $\mathrm{g} \mathrm{kg}^{-1}$ nas folhas de Tupi e 5,14 $\mathrm{g} \mathrm{kg}^{-1} \mathrm{em} \mathrm{IPR}$ 100. Estes resultados não corroboram com os encontrados por Gomes et al. (2018), pois estes concluíram que o AS em plantas de milho (Zea mays) aumentou os teores de clorofila e a biomassa das plantas. Carvalho et al. (2020), também concluíram
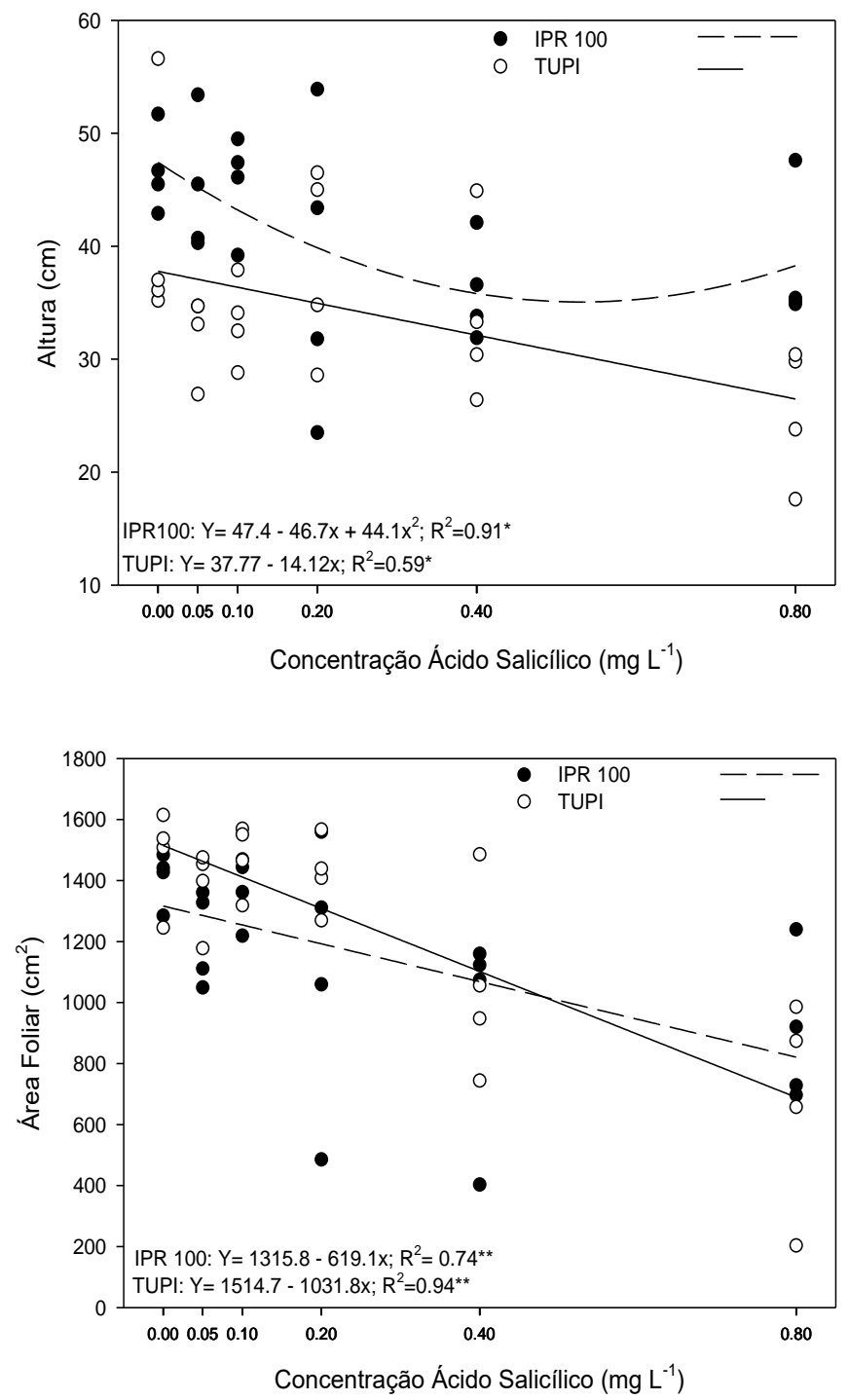

que o teor relativo de água aumentou $44,5 \%$ com aplicação do AS. Apesar do AS ser conhecido como mitigador dos efeitos de estresses abióticos em plantas, nestas duas cultivares de café estudadas ele não assumiu a função de ativar as respostas de defesa da planta.
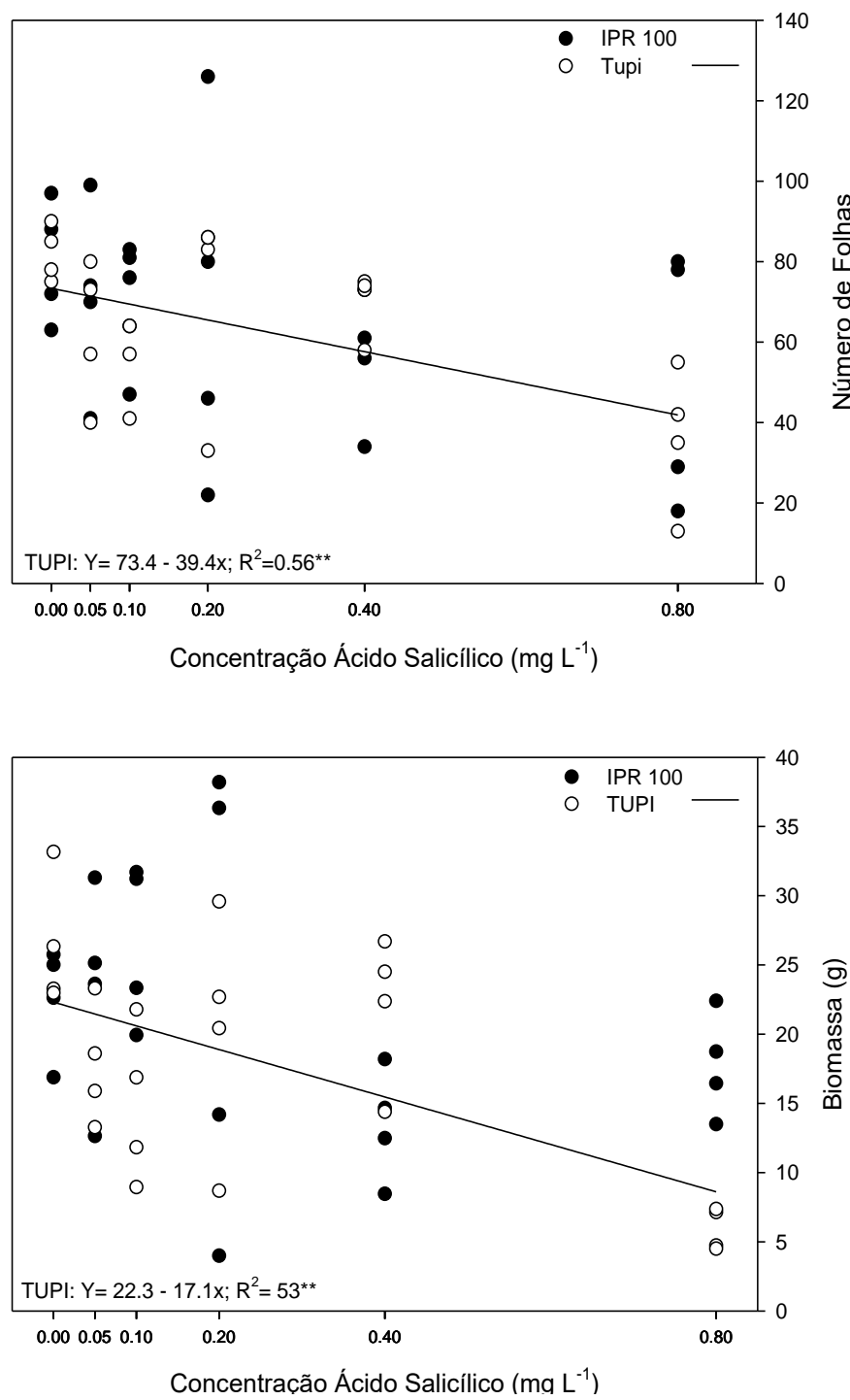

Figura 1. Análise de regressão para altura de planta, número de folhas, área foliar e biomassa total de plantas de cafeeiro sob diferentes concentrações de ácido salicílico déficit hídrico.

Os hormônios vegetais exercem funções determinantes no desenvolvimento das plantas; no entanto, o balanço hormonal é também importante para o adequado metabolismo, pois o desbalanço entre os diferentes hormônios pode resultar em alterações na dominância apical, crescimento da parte aérea e sistema radicular e outros processos (Matos et al., 2019). O AS é um composto fenólico que pode interferir na biossíntese e ação do etileno (Raskin, 1992). Tendo em vista que o etileno exerce efeitos sobre o crescimento da planta é possível concluir que esses resultados corroboram com as informações de 
Kerbauy, (2008), ao afirmar que o AS é um hormônio vegetal que, quando aplicado, pode inibir o crescimento da planta ou aumentá-lo, dependendo da concentração utilizada, da espécie e condições de cultivo. Isto explica as reduções das variáveis relacionadas ao crescimento das plantas de café, como altura de plantas, número de folhas, área foliar e biomassa, com o aumento das concentrações de AS. De acordo com Koo et al. (2020), geralmente, altos níveis de AS regulam negativamente o desenvolvimento e crescimento das plantas.

Tabela 3. Análise de variância e teste de média para teor relativo de água (TRA), transpiração e clorofilas $a$ e $b$ para duas cultivares (IPR 100 e Tupi) de Coffea arabica submetidas a diferentes concentrações de ácido salicílico e sob déficit hídrico.

\begin{tabular}{|c|c|c|c|c|c|}
\hline \multirow{2}{*}{$\begin{array}{l}\text { Fonte de } \\
\text { Variação }\end{array}$} & \multirow[b]{2}{*}{ GL } & \multicolumn{4}{|c|}{ Quadrados Médios } \\
\hline & & TRA & $\begin{array}{l}\text { Transpiração } \\
\left(\mathrm{g} \mathrm{H}_{2} \mathrm{O} \mathrm{dia}^{-1}\right)\end{array}$ & $\begin{array}{c}\mathrm{Cla} \\
\left(\mathrm{g} \mathrm{kg}^{-1}\right)\end{array}$ & $\begin{array}{c}\mathrm{Cl} \mathrm{b} \\
\left(\mathrm{g} \mathrm{kg}^{-1}\right)\end{array}$ \\
\hline Cultivar & 1 & $0,0024^{\mathrm{ns}}$ & $0,0056^{\mathrm{ns}}$ & $0,578^{\mathrm{ns}}$ & $3,05^{\mathrm{ns}}$ \\
\hline Concentração & 5 & $0,0027^{\mathrm{ns}}$ & $0,011^{\mathrm{ns}}$ & $1,06^{\mathrm{ns}}$ & $3,90^{\mathrm{ns}}$ \\
\hline Cult*Conc & 5 & $0,0019^{\mathrm{ns}}$ & $0,021^{\mathrm{ns}}$ & $0,94^{\mathrm{ns}}$ & $1,52^{\mathrm{ns}}$ \\
\hline Resíduo & 36 & 0,002 & 0,017 & 0,68 & 1,87 \\
\hline $\mathrm{CV}(\%)$ & & 28,3 & 140,2 & 25,4 & 25,4 \\
\hline Tratamento & & \multicolumn{4}{|c|}{ Médias } \\
\hline 0 & & $0,15(100 \%)$ & $0,096(100 \%)$ & $3,69(100 \%)$ & $6,35(100 \%)$ \\
\hline 0,05 & & $0,16(107 \%)$ & $0,063(66 \%)$ & $3,18(86 \%)$ & $5,32(84 \%)$ \\
\hline 0,1 & & $0,15(100 \%)$ & $0,034(35 \%)$ & $3,02(82 \%)$ & $5,22(82 \%)$ \\
\hline 0,2 & & $0,14(93 \%)$ & $0,041(43 \%)$ & $5,96(162 \%)$ & $9,60(263 \%)$ \\
\hline 0,4 & & $0,17(113 \%)$ & $0,058(60 \%)$ & 4,91 (133\%) & $8,08(127 \%)$ \\
\hline 0,8 & & $0,19(127 \%)$ & $0,10(104 \%)$ & $2,92(79 \%)$ & $4,56(73 \%)$ \\
\hline
\end{tabular}

*significativo a $5 \%$ de probabilidade; $* *$ significativo a $1 \%$ de probabilidade; $\mathrm{ns}=$ não significativo pelo teste $\mathrm{F}$.

A Tabela 4 demonstra a importância das variáveis analisadas no acúmulo de biomassa de plantas de cafeeiro sob diferentes concentrações de AS e déficit hídrico. Os resultados indicam que a regressão múltipla explica $86 \%$ da variação da biomassa de plantas de cafeeiro. O número de folhas e a razão de massa foliar foram as variáveis mais importantes para o acúmulo de biomassa em plantas de cafeeiro. Estes resultados estão em consonância com os demais apresentados e ratificam que a redução do crescimento da parte aérea contribuiu significativamente para a menor biomassa total de plantas de cafeeiro sob altas concentrações de AS. Os resultados do presente diferem do encontrado por Mazzuchelli et al. (2014), que verificou aumento na altura das plantas de eucalipto (Eucalyptus sp.) para todas as concentrações utilizadas; entretanto, somente a concentração de $300 \mathrm{mg} \mathrm{L}^{-1}$ de AS foi eficiente em promover aumento de área foliar.

A análise de componentes principais (PCA) mostrada na figura 2 , foi realizada com todas as variáveis do trabalho e posteriormente foram descartadas as que tinham alto valor inferior a 0,7. A análise de PCA representa $80,1 \%$ da variação dos dados e ratifica os resultados anteriormente apresentados a exemplo do eixo 1 da PCA em que a biomassa é a variável determinante para este eixo. Observa-se que as plantas tratadas com maiores concentrações de AS apresentaram menores biomassa e estão com os pontos localizados à 
esquerda do eixo 1. No entanto, as plantas dos tratamentos controle estão com os pontos localizados à direita do eixo 1, indicando maior acúmulo de biomassa e as plantas sob baixas concentrações de AS em localização intermediária.

Esta análise de PCA é conclusiva no sentido de afirmar que as elevadas concentrações de AS reduzem o crescimento, mais especificamente, o acúmulo de biomassa de plantas de cafeeiro. Além disto, à efetividade da aplicação AS como elicitor em plantas de cafeeiro para estudos de deficiência hídrica não exerce efeitos na fisiologia das plantas $\mathrm{e}$ consequentemente não assume função de ativar respostas de defesa ao estresse hídrico nestas plantas.
De acordo com Colli, (2008), a aplicação do AS pode inibir a germinação e o crescimento da planta, interferir na absorção das raízes, reduzir a transpiração, causar a abscisão das folhas, alterar o transporte de íons, induzindo uma rápida despolarização das membranas, logicamente dependendo da espécie e sua sensibilidade, com ambiente e das condições de cultivo e da concentração utilizada do hormônio em consideração. Com base nesses resultados, recomenda-se, para serem mantidas em experimentos futuros, as variáveis altura de plantas, número de folhas, área foliar, biomassa e razão de massa radicular.

Tabela 4. Resumo da análise de regressão múltipla para avaliar a importância das variáveis sobre o acúmulo de biomassa de plantas de cafeeiro sob diferentes concentrações de ácido salicílico e déficit hídrico.

\begin{tabular}{|c|c|c|c|c|c|c|}
\hline \multirow[b]{2}{*}{ Biomassa } & \multicolumn{2}{|r|}{$R^{2}=0,86$} & \multicolumn{2}{|c|}{$F(15,32)=12,65$} & \multicolumn{2}{|c|}{$p<0,0000$} \\
\hline & Beta & Std.Err. of Beta & B & Std.Err. of B & t (32) & p-level \\
\hline Intercept & & & 67.37 & 152.33 & 0.44 & 0.66 \\
\hline$N^{o}$ folhas & 0.48 & 0.09 & 0.17 & 0.03 & 5.41 & $0.00 * *$ \\
\hline $\mathrm{CR}$ & 0.12 & 0.08 & 0.29 & 0.18 & 1.58 & 0.12 \\
\hline Área foliar & 0.07 & 0.11 & 0.00 & 0.00 & 0.66 & 0.51 \\
\hline $\mathrm{RMF}$ & -0.72 & 0.09 & -569.51 & 74.65 & -7.63 & $0.00 * *$ \\
\hline $\mathrm{RMC}$ & -0.22 & 0.78 & -15.62 & 54.49 & -0.29 & 0.78 \\
\hline RMR & -0.34 & 0.77 & -24.16 & 53.68 & -0.45 & 0.66 \\
\hline TRA & 0.05 & 0.10 & 0.04 & 0.08 & 0.52 & 0.61 \\
\hline $\mathrm{E}$ & 0.07 & 0.08 & 0.01 & 0.01 & 0.91 & 0.37 \\
\hline $\mathrm{Fv}^{\prime} / \mathrm{Fm}^{\prime}$ & -0.59 & 1.66 & -75.31 & 211.48 & -0.36 & 0.72 \\
\hline $\mathrm{Pe}$ & -0.30 & 0.25 & -49.85 & 42.38 & -1.18 & 0.25 \\
\hline FSII & -0.03 & 2.34 & -3.42 & 233.91 & -0.01 & 0.99 \\
\hline $\mathrm{Fv} / \mathrm{Fm}$ & 0.65 & 0.72 & 83.27 & 91.55 & 0.91 & 0.37 \\
\hline $\mathrm{qP}$ & -0.29 & 1.42 & -34.67 & 171.50 & -0.20 & 0.84 \\
\hline NPQ & 0.03 & 0.08 & 8.79 & 25.59 & 0.34 & 0.73 \\
\hline $\mathrm{Cl}(\mathrm{a}+\mathrm{b})$ & -0.10 & 0.11 & -0.37 & 0.40 & -0.92 & 0.36 \\
\hline
\end{tabular}

*significativo a $5 \%$ de probabilidade; **significativo a $1 \%$ de probabilidade

\section{CONCLUSÕES}

O uso de AS nas concentrações variando de 0,05 a $0,8 \mathrm{mg} \mathrm{L}^{-1}$ reduziu o crescimento e acúmulo de biomassa de plantas de cafeeiro. O AS não ativou os mecanismos de defesa de plantas de cafeeiro sob déficit hídrico e as concentrações testadas influenciaram negativamente nas características fisiológicas das plantas. Dessa forma, a hipótese de ação do regulador vegetal como elicitor não foi 
comprovada no presente estudo; no entanto, por se tratar de um tema inovador e incipiente quanto à informações esclarecedoras, registra-se a necessidade de pesquisas futuras e desenvolvimento de trabalhos com concentrações variadas e efetivas para a reprogramação metabólica e fisiológica das plantas.
Recomenda-se as variáveis altura de plantas, número de folhas, área foliar, biomassa e razão de massa radicular, para serem mantidas em estudos futuros com aplicação de AS em cafeeiro.

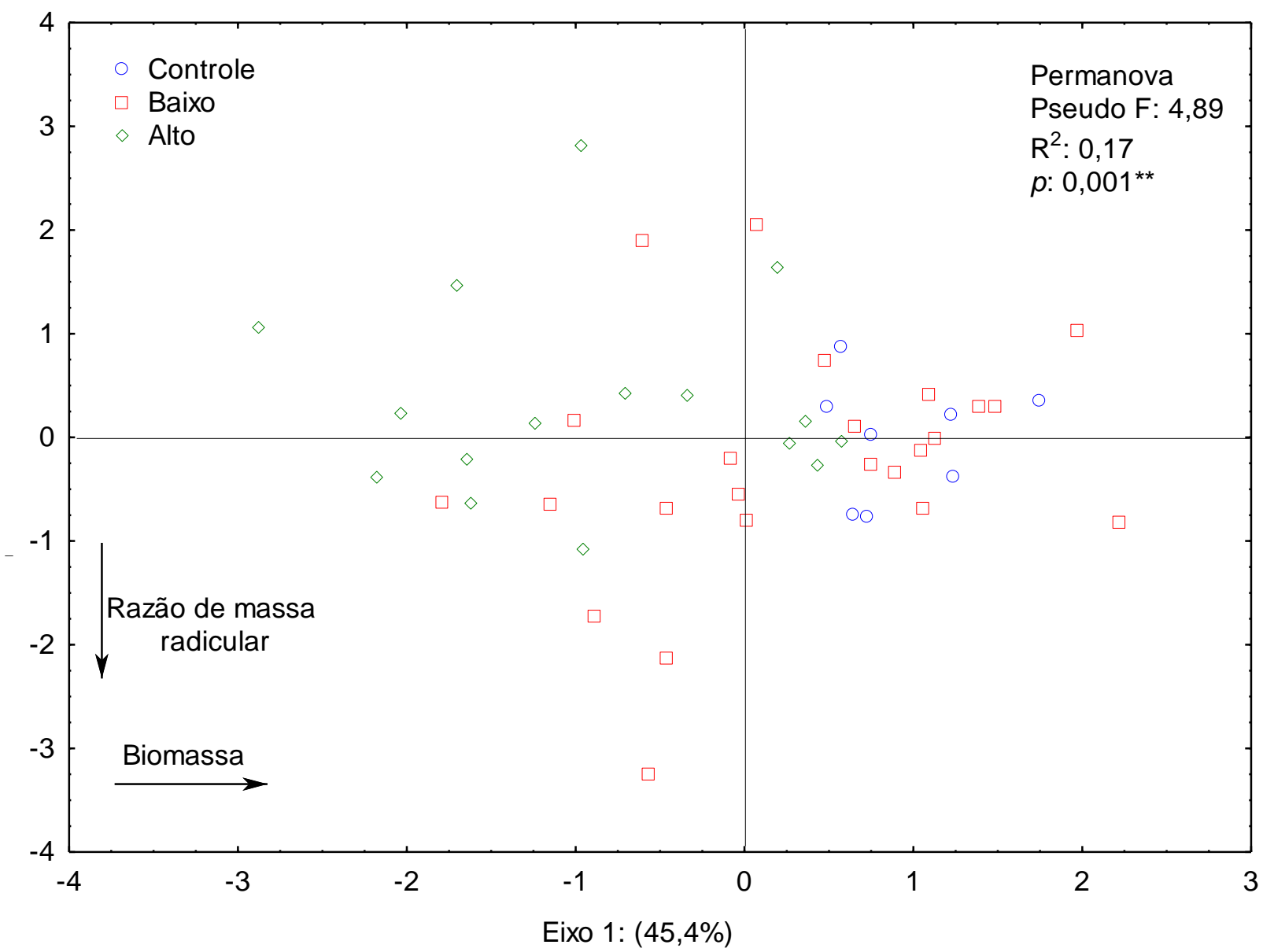

Figura 2. Análise de componentes principais para ordenação das variáveis avaliadas em plantas de cafeeiro sob diferentes concentrações de ácido salicílico e déficit hídrico.

\section{REFERÊNCIAS BIBLIOGRÁFICAS}

Allen, R.G.; Pereira, L.S.; Raes, D. \& Smith, M. (1998). Crop evapotranspiration: guidelines for computing crop water requirements. Rome: FAO, 300p. (FAO. Irrigation and Dranaige Paper, 56).

Alvares, C.A.; Stape, J.L.; Sentelhas, P.C.; Gonçalves, J.L.M. \& Sparovek, G. (2013). Köppen's climate classification map for Brazil.
Meteorologische Zeitschrift 22(6): 711-728. https://doi.org/10.1127/0941-2948/2013/0507

Anderson, M.J. (2001). A new method for nonparametric multivariate analysis of variance. $\begin{array}{llll}\text { Australian } & \text { Ecology 26: 32-46. }\end{array}$ https://doi.org/10.1111/j.14429993.2001.01070.pp.x

Batista, L.A.; Guimaraes, R.J.; Pereira, F.J.; Carvalho, G.R. \& Castro, E.M.D. (2010). Anatomia 
foliar e potencial hídrico na tolerância de cultivares de café ao estresse hídrico. Revista Ciência Agronômica 41(3): 475-481. https://doi.org/10.1590/S1806-66902010000300022

Colli, S. (2008). Outros Reguladores: Brassinosteróides, Poliaminas, Ácidos Jasmônico e Salicílico. In: Kerbauy, G.B. Fisiologia Vegetal. 2. ed. Rio de Janeiro: Guanabara Koogan, p. 296-302.

Carvalho, J.S.B.; Silva, J.P.R. \& Batista, R.deC.M. (2020). Uso do ácido salicílico como atenuador aos efeitos do déficit hídrico em plantas de manjericão. Diversitas Journal, 5(3), 1561-1574. https://doi.org/10.17648/diversitas-journal-v5i3-888

Companhia Nacional de Abastecimento (CONAB) (2018). Acompanhamento da safra brasileira: café. Brasília, quarto levantamento. 5(4): 1-84.

Da Silva, A.C.; Suassuna, J.F.; De Melo, A.S.; Costa, R.R.; De Andrade, W.L. \& Da Silva, D.C. (2017). Salicylic acid as attenuator of drought stress on germination and initial development of sesame. Revista Brasileira de Engenharia Agrícola e Ambiental 21(3): 156-162.

https://doi.org/10.1590/1807-

1929/agriambi.v21n3p156-162

Duarte, R.P.; Rezende, R.K.S.; Pinto, F.; Jesus, M.V.; Da Silva Junior, I.R. \& Scoton, A.M. (2018). In Vitro Priming of Sugarcane Varieties (RB966928 and RB867515). American Journal of Plant Sciences 9: 763-774. https://doi.org/10.4236/ajps.2018.94060

Durán, C.A.; Tsukui, A.; Santos, F.; Martinez, S.T.; Bizzo, H.R. \& Rezende, C.M. (2017). Café: Aspectos Gerais e seu Aproveitamento para além da Bebida. Revista Virtual de Química 9(1): 107-134. https://doi.org/10.21577/1984-6835.20170010

Fernandes, A.L.T.; Partelli, F.L.; Bonomo, R. \& Golynski, A. (2012). A moderna cafeicultura dos cerrados brasileiros. Pesquisa Agropecuária
Tropical

42(2):

231-240.

https://doi.org/10.1590/S1983-40632012000200015

Gomes, C.A.; Assis, A.C. De L.P.; Alves, D.P. \& Reis, M.R.dos. (2018). Aplicação de ácido salicílico como atenuador dos efeitos de déficit hídrico no milho. The Journal of Engineering and Exact Sciences 4(3): 0359-0363. https://doi.org/10.18540/jcecvl4iss3pp0359-0363

Idrees, M.; Khan, M. M. A.; Aftab, T.; Naeem, M. \& Hashmi, N. (2010). Salicylic acid-induced physiological and biochemical changes in lemongrass varieties under water stress. Journal of Plant Interactions, 5(4): 293-303.Kerbauy, G.B. Fisiologia Vegetal. (2008). Rio de Janeiro: Guanabara Koogan 470p.

Koo, Y.M.; Heo, A.Y. \& Choi, H.W. (2020). Salicylic Acid as a Safe Plant Protector and Growth Regulator. The Plant Pathology Journal 36(1): 110.

Lämke, J. \& Bäurle, J. (2017). Epigenetic and chromatin-based mechanisms in environmental stress adaptation and stress memory in plants. Genome Biology, 18(124): 1-11. https://doi.org/10.1186/s13059-017-1263-6

Lima, J.D.; Dedino, D.B.; Guedes, A.T.; da Rosa, F.L.; Lima, G.O.; Lima, N.K.; Pinheiro, C.R. \& da Silva, G.J. (2019). Salicylic acid at beans germination against salt stress. Scientia Agraria Paranaensis 18(1): 88-92.

Martins, L.D.; Eugenio, F.C.; Rodrigues, W.N.; Tomaz, M.A.; Santos, A.R. \& Ramalho, J.C. (2018). Carbon and water footprints in Brazilian coffee plantations-the spatial and temporal distribution. Emirates Journal of Food and Agriculture 30(6): 482-487.

Matos, F.S.; Borges, L.P.; Amaro, C.L.; De Oliveira, D.B.; Do Carmo, M.S. \& Torres Junior, H.D. (2019). 
Folha Seca: Introdução à Fisiologia Vegetal. $1^{\text {a }}$ ed. Curitiba, PR: Appris. 189 p.

Mazzuchelli, E.H.L.; Souza, G.M. \& Pacheco, A.C. (2014). Rustificação de mudas de eucalipto via aplicação de ácido salicílico. Pesquisa Agropecuária Tropical 44(4): 443-450. https://doi.org/10.1590/S1983-40632014000400012

Ministério da Agricultura e Meio Ambiente (MAPA). (2015).

Disponível<http://www.agricultura.gov.br/comunica cao/noticias/2015/04/exportacao-de-cafe-crescemais-de-35porcento-nos-tres-primeiros-meses-de$\underline{2015>}$.

Raskin, I. (1992). Role of salicylic acid in plants. Annual Revie of Plant Physiology and Plant Molecular Biology 43: 439-463. https://doi.org/10.1146/annurev.pp.43.060192.00225 $\underline{5}$

Ribeiro, A.F.F.; Matsumoto, S.N.; Ramos, P.A.S.; Dos Santos, J.L.D.; Teixeira, E.C.; D’arêde, L.O. \& Viana, A.E. (2017). Paclobutrazol e restrição hídrica no crescimento e desenvolvimento de plantas de café. Coffee Science 12(4): 534-543. https://doi.org/10.25186/cs.v12i4.1361

Samota, M. K.; Sasi, M. \& Singh, A. (2017). Impact of Seed Priming on Proline Content and Antioxidant Enzymes to Mitigate Drought Stress in Rice Genotype. International Journal of Current Microbiology and Applied Sciences 6(5): 24592466. https://doi.org/10.20546/ijcmas.2017.605.275 Sharma, A. \& Bhardwaj, R. D. (2014). Effect of seed pre-treatment with varying concentrations of salicylic acid on antioxidant response of wheat seedlings. Indian Journal of Plant Physiology, 19(3): 205209. https://doi.org/10.1007/s40502-014-0100-0

Silva, L.G.; Castanheira, D.T.; Voltolini, G.B.; Souza, I.F.D.; Gonçalves, A.H. \& Guimarães, R.J. (2017). Sintomas de fitotoxicidade e crescimento de mudas de café submetidas aos herbicidas inibidores da protox. Coffee Science 12(3): 290-296.

Smith, M. (1991). Report on the expert consultation on revision of FAO methodologies for crop water requiremebts. Rome FAO. 45p.

Sokal, R.R. \& Rolf, F.J. (1995). Biometry. Third edition. W. H. Freeman, New York.

Systat Software. (2006). SigmaPlot for windows. Version 10.0. San Jose: Systat Software.

Statsoft, Inc. Statistica (data analysis software system), version 7. 2007. Disponível em: < http://www.statsoft.com/Products/STATISTICA-

Features>.

Taiz, L.; Zeiger, E.; Moller, I.M. \& Murphy, A. (2017). Fisiologia vegetal. 6 ed. Porto Alegre: ArtMed, 858p.

Wellburn, A.R. (1994). The spectral determination of chlorophylls a and b, as well as total carotenoids, using various solvents with spectrophotometers of different resolution. Journal of Plant Physiology 144(3): 307-313. https://doi.org/10.1016/S0176$\underline{1617(11) 81192-2}$ 